\title{
Free Fatty Acid Oxidation and Carnitine
}

\section{Levels in Diphtheritic Guinea Pig Myocardium}

\author{
David R. Challoner and Hans G. Prols \\ From the Departments of Medicine and Biochemistry, Indiana University \\ Medical Center, Indianapolis, Indiana 46202
}

A B S TRACT Previous studies from this laboratory and by Wittels and Bressler have suggested that myocardial carnitine depletion and an accompanying decrease in fatty acid oxidation may contribute to the myocardial disease associated with diphtheria. In addition, administration of carnitine was found to prolong survival of diphtheritic guinea pigs and improve ventricular function in diphtheritic dogs.

The present studies document the hypothesis that the defect in myocardial carnitine, directly assayed, could be repleted in diphtheritic guinea pigs to whom carnitine was administered intraperitoneally. The decreased fatty acid oxidation previously reported only for homogenates was confirmed in an isolated perfused diphtheritic guinea pig heart preparation. The addition of L-carnitine to this perfusate augmented fatty acid oxidation to normal levels.

Taken together, these and previous studies would support a pathogenetic role for carnitine depletion in diphtheritic myocarditis and suggest the possibility of experimental therapy with L-carnitine.

\section{INTRODUCTION}

Previous studies by Wittels and Bressler have demonstrated depletion of tissue carnitine in myocardium from diphtheritic guinea pigs $(1,2)$. This depletion was accompanied by a decrease in fatty acid oxidation by myocardial homogenates which could be restored towards normal by the addition of L-carnitine to the incubation. Thus, one hypothesis might be that "starvation" of myocardial mitochondria for free fatty acid (FFA), their transport into mitochondria being dependent upon carnitine, might contribute to the pathophysiology of the myocardial disease caused by diphtheria toxin. In vivo studies from our laboratories have demonstrated that L-carnitine decreases mortality and

Received for publication 7 February 1972 and in revised form 13 March 1972. prolongs the survival of guinea pigs given diphtheria toxin (3). Furthermore, infusion of L-carnitine in diphtheritic dogs led to improvement in left ventricular function curves and cardiac output. Taken together, these studies and those on guinea pig myocardial homogenates would support a pathogenetic role for carnitine depletion in diphtheritic myocarditis.

The present studies were designed to determine if myocardial carnitine, directly assayed, was actually repleted under those conditions where guinea pig survival was prolonged by exogenous administration. Further evidence that extracellular carnitine reaches the intracellular site of its normal physiologic activity was sought by the addition of L-carnitine to the perfusate of an isolated guinea pig heart preparation. The diminished fatty acid oxidation reported for homogenized diphtheritic hearts was confirmed in this intact perfused preparation.

\section{METHODS}

Preparation of animals. Guinea pigs weighing $250 \mathrm{~g}$ were obtained from Paul Hamm Rabbitry, Greenwood, Ind. Diphtheritic animals were prepared by intraperitoneal injection of 2 LDso's of diphtheria toxin (Lilly Lot \#G02732, Eli Lilly and Co., Indianapolis, Ind.) (3). Within 48 to $72 \mathrm{hr}, 50$ $90 \%$ of these animals were obviously sick and manifested indolence, if not complete prostration, diarrhea, occasionally bloody, conjunctivitis, and internal hemorrhage. Some had already expired. Only the sick animals were chosen for study as donors of diphtheritic hearts.

Heart perfusion. Experimental animals were killed by decapitation. The hearts were immediately removed and perfused with a modified recirculating retrograde aortic (Langendorff) technique as described by Morgan, Henderson, Regan, and Parks (4) and previously used (5). Hearts were first perfused for $5 \mathrm{~min}$ with Krebs bicarbonate buffer in a separate chamber and then placed in the closed recirculating chamber containing $20 \mathrm{ml}$ of Krebs bicarbonate buffer, $0.5 \mathrm{~g}$ Armour bovine serum albumin (Armour Pharmaceutical Co., Chicago, Ill.), and $0.2 \mathrm{~mm}$ palmitate-1-14 $\mathrm{C}$. Total FFA concentration was approximately $0.25 \mathrm{~mm}$. Gassing was continuous with $95 \% \mathrm{O}_{2}-5 \% \mathrm{CO}_{2}$. Heart rates in the diphtheritic and normal groups were similar. Effluent $\mathrm{CO}_{2}$ was 
trapped in $8 \mathrm{ml}$ of ethanolamine-ethylene glycol monomethyl ether $(\mathrm{v} / \mathrm{v} 1: 7)(6)$ and radioactivity determined after addition of $10 \mathrm{ml}$ of scintillation medium containing $7.2 \mathrm{~g}$ of 2,5 diphenyloxazole and $0.18 \mathrm{~g}$ of $p$-bis $\{2-(5$ phenyloxazoyl)\}-benzene per liter of toluene. Counting efficiency was determined by internal standardization. The ethanolamine traps were changed every $10 \mathrm{~min}$ for the first $50 \mathrm{~min}$ of the perfusion. The perfusion was terminated at $60 \mathrm{~min}$ by stopping the pump and then switching to nitrogen gassing to wash out the chamber for another $5 \mathrm{~min}$. At $65 \mathrm{~min}$ the perfusate was quickly drained to another chamber, $3 \mathrm{ml}$ of $5 \mathrm{~N}_{2} \mathrm{SO}_{4}$ was added, and the solution was bubbled with $\mathrm{N}_{2}$ for an additional $10 \mathrm{~min}$ into a final $\mathrm{CO}_{2}$ trapping vial.

Where indicated, L-carnitine (Nutritional Biochemicals Corporation, Cleveland, Ohio), in a final concentration of $10 \mathrm{mM}$, was added to the perfusate after $30 \mathrm{~min}$ and the perfusion continued for $30 \mathrm{~min}$ as above. This concentration was chosen from preliminary experiments as one producing an easily observable effect in vitro and yet not having toxic effects on the perfused heart, i.e., decreased heart rate and increased perfusion pressure.

Based on the initial specific activity of palmitate in the perfusate, radioactivity trapped as $\mathrm{CO}_{2}$ as converted to micromoles of palmitate oxidized per gram dry weight of heart. Data are presented as cumulative amounts of palmitate trapped as $\mathrm{CO}_{2}$ with time, and the final figure includes that ${ }^{14} \mathrm{CO}_{2}$ recovered during the "washout" periods from 60 to $75 \mathrm{~min}$.

Myocardial tissue palmitic acid determination. Hearts were removed from similar groups of normal and diphtheritic guinea pigs and perfused with the labeled buffer for $45 \mathrm{~min}$ with and without carnitine addition at $30 \mathrm{~min}$. The hearts were homogenized and extracted in an isopropyl alcohol: heptane : $1 \mathrm{~N} \mathrm{H}_{2} \mathrm{SO}_{4}$ mixture (7) and the final heptane phase taken to dryness. The methyl ester was prepared by the method of Morrison and Smith (8). The samples were run on a Hewlett-Packard (Hewlett-Packard Co., Palo Alto, Calif.) gas-liquid Chromatograph with a 6-ft glass column containing 110-200 mesh Chromosorb W coated with a $15 \%$ suspension of ethylene glycol succinate. Oven tem-

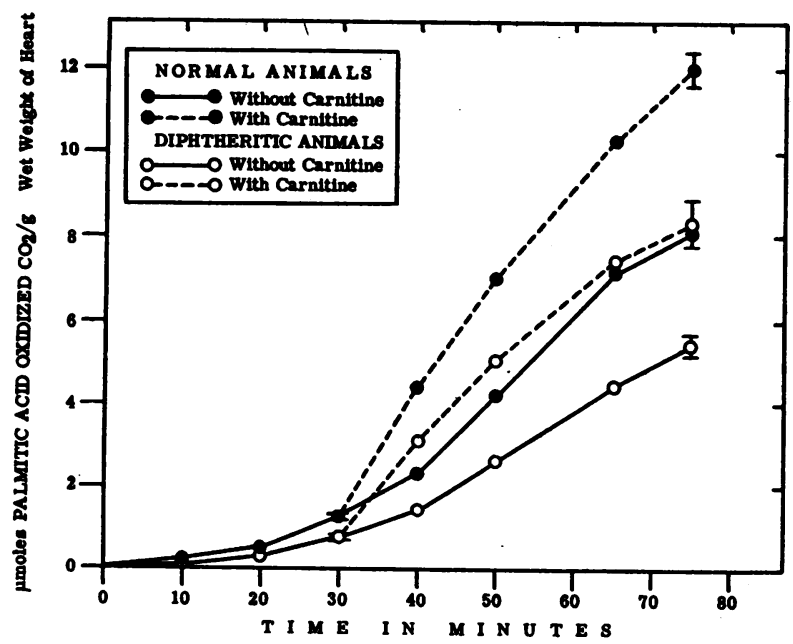

Figure 1 Oxidation of palmitate by guinea pig heart. Hearts were perfused as described in Methods and L-carnitine added to a final concentration of $10 \mathrm{mM}$ at $30 \mathrm{~min}$ of perfusion where indicated. Brackets represent \pm SEM. perature was $170^{\circ} \mathrm{C}$. Samples were detected by a flame detector using argon as the carrier gas. Quantitation was accomplished by a Hewlett-Packard digital integrator (Hewlett-Packard Co., Palo Alto, Calif.). Identification of fatty acid methyl esters was obtained using pure standards from applied science. Radioactivity of the fatty acid peaks was determined directly after stream splitting in a NuclearChicago gas-liquid chromatograph scintillation counter ( $\mathrm{Nu}$ clear-Chicago Corporation, Des Plaines, Ill.) utilizing methane as the carrier.

Determination of myocardial carnitine levels. Groups of 14 animals each were prepared as follows: Normal control, normal $+25 \mathrm{mg}$ L-carnitine intraperitoneally twice daily, diphtheritic (prepared as above), and diphtheritic + carnitine. The animals were sacrificed after 4 days and the hearts removed and frozen in dry ice. Total, insoluble, soluble, and free-carnitine fractions were then determined by extraction as described by Pearson and Tubbs (9). The enzymatic assay was based on that of Marquis and Fritz (10) as modified by Boehringer, Mannheim Corp., New York, to measure the absorbance of free $\mathrm{CoA}$ at $233 \mathrm{~nm}$.

Results are all expressed as mean \pm standard error and probabilities determined by use of the Students $t$ test.

\section{RESULTS}

Isolated perfused guinea pig hearts oxidized palmitic acid- $1{ }^{14} \mathrm{C}$ to ${ }^{14} \mathrm{CO}_{2}$ as demonstrated in Fig. 1 and Table I. The total radioactivity accumulated slowly over the first $30 \mathrm{~min}$ of perfusion, but reached a linear rate between 25 and $30 \mathrm{~min}$ of perfusion which continued for the last $30 \mathrm{~min}$ of perfusion. Similar kinetics were found for hearts from diphtheritic animals. The difference in rate of appearance of label in the $\mathrm{CO}_{2}$ trap in the two 30-min periods does not reflect an increase in total oxidative metabolism since determination of $\mathrm{QO}_{2}$ on a few sample hearts showed no significant change in the second 30 -min period. Therefore, the low rates during the first $25-30$ min probably reflect the kinetics of equilibration of the isotope throughout its transit pools (tissue FFA, dissolved $\mathrm{CO}_{2}$, gas phase $\mathrm{CO}_{2}$ ) before its final appearance in the gas exit trap. Thus only the final values truly determine all of the labeled palmitate oxidized at any point in time and these are presented in Table I. However, even during its initial lag phase, it could be seen that diphtheritic hearts had oxidized the equivalent of $0.825 \pm 0.12 \mu$ moles of palmitic acid/g dry wt, while normal hearts had oxidized almost $50 \%$ more, $1.27 \pm 0.10 \mu$ moles $/ \mathrm{g}$ dry wt, $P=0.002$. These same proportional differences persisted over the final 30 min of perfusion, so that at termination diphtheritic hearts had oxidized $5.38 \pm 0.49$ $\mu$ moles of palmitic acid while normal hearts had oxidized 8.26 $\pm 0.72 \mu$ moles, $P=0.02$.

In other groups of animals, L-carnitine was added to the perfusate to a final concentration of $10 \mathrm{~mm}$ at 30 min of perfusion. An increased rate of oxidation of palmitate can be seen by the next 10-min sample of the $\mathrm{CO}_{2}$ trap in both normal and diphtheritic hearts. The 
TABLE I

${ }^{14} \mathrm{CO}$ Produced from Palmitate $1{ }^{14} \mathrm{C}$ by Perfused Guinea Pig Heart

\begin{tabular}{|c|c|c|c|c|c|}
\hline Minutes & $\begin{array}{l}\text { Normal } \\
(\mathrm{N})\end{array}$ & $\mathbf{n}$ & $\begin{array}{l}\text { Diphtheritic } \\
\text { (D) }\end{array}$ & $\mathbf{n}$ & $P$ (N vs. $\mathrm{D})$ \\
\hline & $\mu m o l e s / 8 d r y$ wt & & $\mu m o l e s / 8 d r y$ wt & & \\
\hline $0-30$ & $1.27 \pm 0.10$ & 17 & $0.825 \pm 0.12$ & 22 & $<0.002$ \\
\hline \multicolumn{6}{|l|}{$30-60$} \\
\hline No addition & $8.26 \pm 0.72^{*}$ & 11 & $5.38 \pm 0.49 \ddagger$ & 14 & $<0.02$ \\
\hline + L-Carnitine & $11.8 \pm 0.78^{*}$ & 6 & $8.30 \pm 1.14 \ddagger$ & 8 & $<0.1$ \\
\hline
\end{tabular}

Values are mean \pm SEM.

${ }^{*} P<0.05$, normal hearts, no addition vs. L-carnitine.

$\ddagger P<0.05$, diphtheritic hearts, no addition vs. L-carnitine.

addition of carnitine to diphtheritic hearts increased total palmitate oxidation to $8.30 \pm 1.14 \mu$ moles, almost exactly that value seen in normal hearts. The addition of carnitine to the perfusate similarly augmented the appearance of palmitate counts in $\mathrm{CO}_{2}$ in normal hearts, with a final value of $11.8 \pm 0.78 \mu$ moles of palmitate oxidized. The increases caused by carnitine over the respective controls were both significant at $P=0.05$. However, the final difference between normal and diphtheritic hearts with carnitine present was not statistically significant, most likely because of smaller numbers in each group as compared with the other studies.

To determine if the change in palmitic acid oxidation seen with carnitine and/or diphtheria might have been due to significant changes in the size or specific activity of the tissue palmitic acid precursor pool through which isotope must pass, total tissue palmitic acid levels were measured. The point of $45 \mathrm{~min}$ was chosen as the midpoint of the major experimental period where isotope effects were seen. The results are shown in Table II.

The tissue pool of palmitic acid was less in diphtheritic than in normal animals after $45 \mathrm{~min}$ of per- fusion in our system. The addition of carnitine at 30 min increased the pool size in normal animals and did not change that in diphtheritic animals. The specific activities of these palmitic acid pools were essentially identical in both conditions and, except for normal animals where there was some decrease, remained unchanged with carnitine.

L-Carnitine was administered intraperitoneally to separate groups of diphtheritic and normal animals exactly as in previous mortality studies where an increase in LDso of diphtheria toxin was demonstrated (3). Carnitine content of guinea pig hearts was determined as described in the Methods section. The results are presented in Table III. Soluble carnitine is that portion soluble in percholoric acid and contains various shortchain fatty acyl carnitine esters and free carnitine. Insoluble carnitine represents that fraction made up of long-chain fatty acyl esters of carnitine (9).

The total myocardial carnitine was decreased from $2.57 \pm 0.15$ to $1.82 \pm 0.05 \mu$ moles $/ \mathrm{g}$ wet wt in the diphtheritic animals. All fractions participated in this drop in a quantitatively equal fashion. However, the proportional decrease in the insoluble fraction was $50 \%$ in

TABLE II

Tissue Levels of Palmitic Acid

\begin{tabular}{|c|c|c|c|c|}
\hline & \multirow{2}{*}{$\begin{array}{l}\text { Normal } \\
(N)\end{array}$} & \multirow{2}{*}{$\begin{array}{l}\text { Diphtheritic } \\
\text { (D) }\end{array}$} & \multicolumn{2}{|c|}{ Specific activity } \\
\hline & & & Normal & Diphtheritic \\
\hline & Mmoles $/ \mathrm{g}$ wet wot & & & \\
\hline 45 min perfusion $(0)$ & $0.10 \pm 0.01^{*}$ & $0.05 \pm 0.008 \ddagger$ & $1.11 \pm 0.10$ & $0.94 \pm 0.24$ \\
\hline $\begin{array}{l}45 \text { min perfusion with carnitine addition } \\
\text { at } 30 \mathrm{~min}(+C)\end{array}$ & $0.14 \pm 0.001 \S$ & $0.05 \pm 0.008 \S$ & $0.72 \pm 0.06$ & $1.06 \pm 0.17$ \\
\hline
\end{tabular}

Myocardial levels of palmitic acid and its specific activity were determined after extraction by gas-liquid chromatography using a ${ }^{4} \mathrm{C}$ detection. $\mathrm{n}=6$ in each group. Values are mean \pm SEM. Significant differences in tissue levels are listed:

$* P<0.02, \mathrm{~N}, \mathrm{O}$ vs. $+\mathrm{C}$.

$\ddagger P<0.005, \mathrm{O}, \mathrm{N}$ vs. $\mathrm{D}$.

$\S P<0.001,+\mathrm{C}, \mathrm{N}$ vs. D. 
TABLE III

Carnitine Content of Guinea Pig Heart

\begin{tabular}{|c|c|c|c|c|c|c|}
\hline Animals & $\mathbf{n}$ & & Free & Soluble & Insoluble & Total \\
\hline & & & \multicolumn{4}{|c|}{$\mu m o l e s / g$ wet wt } \\
\hline \multirow[t]{4}{*}{ 1. Normal } & 16 & & $1.11 \pm 0.11$ & $1.96 \pm 0.11$ & $0.61 \pm 0.05$ & $2.57 \pm 0.15$ \\
\hline & & $P$ (1 vs. 2$)$ & $<0.1$ & $<0.005$ & $<0.001$ & $<0.001$ \\
\hline & & $P(1$ vs. 3$)$ & NS & NS & NS & NS \\
\hline & & $P(1$ vs. 4$)$ & NS & $<0.05$ & $<0.05$ & NS \\
\hline \multirow[t]{3}{*}{ 2. Diphtheritic } & 14 & & $0.87 \pm 0.07$ & $1.51 \pm 0.05$ & $0.31 \pm 0.03$ & $1.82 \pm 0.05$ \\
\hline & & $P$ (2 vs. 3$)$ & $<0.1$ & $<0.005$ & $<0.001$ & $<0.001$ \\
\hline & & $P(2$ vs. 4$)$ & $<0.005$ & $<0.001$ & $<0.01$ & $<0.001$ \\
\hline \multirow[t]{2}{*}{ 3. Diphtheritic + carnitine } & 14 & & $1.08 \pm 0.06$ & $1.95 \pm 0.13$ & $0.55 \pm 0.05$ & $2.50 \pm 0.12$ \\
\hline & & $P$ (3 vs. 4$)$ & $<0.1$ & $<0.05$ & NS & $<0.1$ \\
\hline 4. Normal + carnitine & 14 & & $1.32 \pm 0.10$ & $2.42 \pm 0.18$ & $0.46 \pm 0.04$ & $2.88 \pm 0.16$ \\
\hline
\end{tabular}

Values are mean \pm SEM.

the diphtheritic animals as compared to the normal and was the most dramatic change when considered in this fashion. Administration of carnitine to diphtheritic animals returned all fractions to normal levels; and when compared with the diphtheritic control levels, the increase was statistically significant in all fractions except the free fraction. The administration of Lcarnitine to normal animals increased all fractions slightly, but the increase in the total carnitine was not significant, and the other increases were of only marginal significance.

All of the above results have been expressed as grams per wet weight and separate determination of wet weight-dry weight ratio between diphtheritic and normal guinea pig hearts showed no significant difference, so these results cannot be attributed to increased myocardial edema.

\section{DISCUSSION}

Previous studies by Wittels and Bressler demonstrated decreased tissue carnitine and depressed fatty acid oxidation in homogenized diphtheritic guinea pig hearts $(1,2)$. We have subsequently demonstrated that Lcarnitine administration partially prevents the mortality of diphtheria toxin in guinea pigs and acutely improves depressed cardiovascular function in diphtheritic dogs (3). Therefore, one possible hypothesis to explain the myocardial disease of Corynebacterium diphtheriae infection and the effects of L-carnitine described above would be: $(a)$ that diphtheria toxin causes depletion of myocardial carnitine via some mechanism; $(b)$ that this leads to "starvation" of myocardium due to depression of carnitine-dependent oxidation of long-chain FFA, a preferred substrate. and $(c)$ that this latter defect can be at least partially repleted by exogenous administration of L-carnitine. The present studies were undertaken to provide further evidence for this hypothesis by the study of FFA metabolism in intact perfused guinea pig hearts, since all previous studies had been on myocardial homogenates. In addition, data were obtained by direct assay to determine if myocardial carnitine levels are indeed repleted when L-carnitine is administered in vivo in a fashion similar to that shown to improve survival in our previous studies in diphtheritic guinea pigs. Finally we determined whether exogenous carnitine could get to the site of its intracellular function by direct measurement.

As with all metabolic studies using isotope flux, care must be taken that changes in precursor pool size or alternative unlabeled contributions to the precursor pool do not lead to incorrect interpretations of oxidative rates. In the present studies, total isotope flux indicates the oxidation of 5-10 $\mu$ moles of palmitic acid/ hr per $\mathrm{g}$ dry wt of heart (Table I), or the equivalent

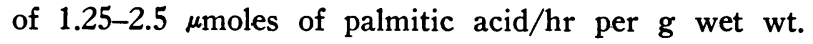
We attempted to evaluate the immediate oxidative precursor pool directly by assay of total tissue free palmitic acid and its specific activity. The decrease in palmitic acid pool size in diphtheritic hearts, if anything, would tend to dilute exogenous isotope less than in normal hearts and therefore lends support to the interpretation of a true decrease in fatty acid oxidation rate in diphtheritic hearts. Also with similar specific activities in the immediate oxidative precursor pools, the ${ }^{14} \mathrm{CO}_{2}$ appearance curves may be taken as representative of true oxidative rates.

The present results demonstrate that palmitate oxidation by diphtheritic guinea pig hearts occurred at a level only $65 \%$ of that of normal guinea pig hearts.

The addition of $10 \mathrm{~mm}$ carnitine to the perfusion medium significantly augmented palmitate oxidation by diphtheritic hearts by $54 \%$ to a level almost exactly similar to that found in normal hearts without added carnitine. Tissue palmitate levels and specific activity 
were unchanged. These observations indicate an absolute increase in palmitate oxidation in diphtheritic hearts and imply both that the lesion can be corrected and that exogenous carnitine must obtain access to its intracellular site of physiologic activity.

To be noted, however, was that L-carnitine addition to the perfusate of normal hearts also stimulated palmitate oxidation, in this case, by a somewhat lesser amount, $43 \%$. These results are similar to those previously reported in myocardial homogenates by Wittels and Bressler $(1,2)$. The "normalization" of fatty acid oxidation in the diphtheritic guinea pig hearts by carnitine must be considered in the light of this ability of Lcarnitine to stimulate in vitro palmitate oxidation to "supernormal" levels in control hearts.

It is possible that carnitine supply is generally a rate-limiting factor for fatty acyl oxidation in the normal whole animal as well as in our in vitro systems, since the administration of carnitine to humans, rats, mice, and guinea pigs augments oxidation of various chain-length fatty acyl groups $(3,11-15)$. In this sense, the carnitine effect may be nonspecific, though the mortality studies and acute effects described previously in diphtheritic animals suggest that augmentation of FFA oxidation back to "normal" is associated with a beneficial biologic effect. Though we do not have dose-response studies to define maximal responses to carnitine in control and diphtheritic hearts, the present studies at a single concentration suggest that there may be additional limiting factors for palmitate oxidation in the diphtheritic hearts, as also discussed below.

The present results with L-carnitine in the guinea pig heart perfusion system are quite different from those previously demonstrated in rat heart by Rodis, D'Amato, Koch, and Vahouny where, if anything, a depression of palmitate oxidation was demonstrated (16). Possible explanations to be considered are that the systems might be somewhat different but particularly that those investigators utilized a D,L-carnitine mixture, not L-carnitine, the physiologic isomer.

Why the tissue pool of palmitic acid would be smaller in diphtheritic hearts in the face of a decreased oxidative rate is unknown, but other results from this laboratory (in preparation) suggest that diphtheritic animals develop a decrease in blood FFA levels during the progression of the disease, possibly due to a defect in lipolysis in adipose tissue. Perhaps a similar defect in endogenous myocardial lipolysis occurs causing a decrease in tissue pool size in the face of decreased oxidation, although the lack of changes in specific activity would not support this supposition. Alternatively, a defect in FFA transport or uptake may occur since diphtheria toxin is known to be a more general cellular poison as an inhibitor of protein synthesis $(17,18)$.
Regardless of mechanism, these results and those in perfused hearts discussed above suggest that additional factors other than just carnitine depletion contribute to the diminished fatty acid oxidation in diphtheria. Though the quantitative contributions of each cannot be assessed, it should be stressed that carnitine administration to diphtheritic animals is associated with a beneficial biologic effect.

The total myocardial carnitine in diphtheritic hearts was found to be $71 \%$ of that found in normal hearts. This decrease might be compared with the reduction of $65 \%$ of normal fatty acid oxidation demonstrated in the perfusion studies, although there is no other evidence at other concentrations of carnitine that these observations necessarily change in parallel. The insoluble fraction represents predominantly long-chain fatty acyl carnitine esters and presumably would be the most immediate precursor pool for transmitochondrial transport and fatty acid oxidation. This pool was found to be $50 \%$ of normal in diphtheritic myocardium again deserving quantitative comparison with the decrease in FFA oxidation. Of great interest was the finding that the intraperitoneal administration of $25 \mathrm{mg}$ of carnitine twice daily to guinea pigs maintained both their total carnitine content and the $a b$ solute values of the subfractions at completely normal levels. These data also suggest that, in the intact animal, exogenous L-carnitine can obtain access to its intracellular sites of physiologic activity. In normal animals, with the exception of the insoluble fraction, the administration of L-carnitine augmented all fractions only slightly and with marginal or no statistical significance (total).

These results thus confirm in an intact heart the previous report by Wittels and Bressler that myocardial palmitate oxidation was diminished in homogenized diphtheritic myocardium and that this reduction was correlated with a decrease in tissue carnitine levels $(1,2)$. The present data demonstrate that intraperitoneal administration of carnitine given in identical fashion to those studies in which we demonstrated both prolonged survival and doubling of the LDso of diphtheria toxin can return myocardial carnitine levels to normal. This is further support for the hypothesis that the therapeutic effect of exogenous L-carnitine may well be by crossing the cell membrane to supplement the diminished pool at its site of physiologic activity. This augments a diminished fatty acid oxidation which had contributed in some fashion to the total picture of myocardial failure in diphtheritic myocardium. As we have discussed previously (3), this defect may be secondary to another welldocumented effect of diphtheria toxin to inhibit protein synthesis $(17,18)$, but may be the more immediate contributor to mortality. If fatty acid oxidation can be maintained by carnitine administration, the defect in protein synthesis may have some capacity for self-repair. 


\section{ACKNOWLEDGMENTS}

The careful technical assistance of Miss Anne Fletcher and editorial assistance of Miss Olive Evans added greatly to this investigation. Support from the following sources is gratefully acknowledged: HE063808 and AM-11805 from the National Institutes of Health and a grant from the Indiana Heart Association.

\section{REFERENCES}

1. Wittels, -B., and R. J. Bressler. 1964. Biochemical lesion of diphtheria toxin in the heart. J. Clin. Invest. 43: 630 .

2. Bressler, R., and B. Wittels. 1965. The effect of diphtheria toxin on carnitine metabolism in the heart. Biochim. Biophys. Acta. 104 : 39.

3. Challoner, D., I. Mandelbaum, and W. Elliott. 1971. Protective effect of L-carnitine in experimental intoxication with diphtheria toxin. J. Lab. Clin. Med. 77: 616.

4. Morgan, H. E., M. J. Henderson, D. M. Regan, and C. R. Parks. 1961. Regulation of glucose uptake in muscle. J. Biol. Chem. 236: 253.

5. Challoner, D. R., and D. Steinberg. 1966. Oxidative metabolism of myocardium as influenced by fatty acids and epinephrine. Am. J. Physiol. 211: 897.

6. Jeffay, H., and J. Alvarez. 1961. Liquid scintillation counting of carbon-14 use of ethanolamine-ethylene glycol monomethyl ether-toluene. Anal. Chem. 33: 612 .

7. Hagenfeldt, L. 1966. A gas chromatographic method for the determination of individual free fatty acids in plasma. Clin. Chim. Acta. 13: 266.
8. Morrison, W., and L. Smith. 1964. Preparation of fatty acid methyl esters and dimethylacetals from lipids with boron fluoride-methanol. J. Lipid Res. 5: 600 .

9. Pearson, D. J., and P. K. Tubbs. 1964. Tissue levels of acid insoluble carnitine in rat heart. Biochim. Biophys. Acta. 84 : 772.

10. Marquis, N. R., and I. B. Fritz. 1964. Enzymological determination of free carnitine concentrations in rat tissues. J. Lipid Res. 5 : 184.

11. Garland, P. B., and P. J. Randle. 1964. Regulation of glucose uptake by muscle. Biochem. J. 93: 678 .

12. Kreisberg, R. S. 1966. Effect of diabetes and starvation on myocardial triglyceride and free fatty acid utilization. Am. J. Physiol. 210: 379.

13. Gravina, E., and G. Sanvitale. 1969. Effect of carnitine on blood acetoacetate in fasting children. Clin. Chim. Acta. 23 : 376.

14. Soling, H., and A. Aygels. 1968. Effects of L-carnitine on utilization of ketone bodies and glucose in eviserated nephrectomized rats. Biochim. Biophys. Acta. 158: 162.

15. Miller, W., and J. Krake. 1962. Studies on lipid metabolism in mice treated with carnitine. Proc. Soc. Exp. Biol. Med. 109 : 215.

16. Rodis, S. L., P. H. D'Amato, E. Koch, and G. V. Vahouny. 1970. Effect of carnitine on uptake, oxidation and esterification of palmitate by the perfused rat heart. Proc. Soc. Exp. Biol. Med. 133: 1973.

17. Baseman, J. B., A. M. Papenheimer, D. M. Gill, and A. A. Harper. 1970. Action of diphtheria toxin in the guinea pig. J. Exp. Med. 132: 1138.

18. Bonventre, P. F., and J. G. Imhoff. 1966. Studies on the mode of action of diphtheria toxin. I. Protein synthesis in guinea pig tissue. J. Exp. Med. 124: 1107. 